CASE REPORT

\title{
Presentation of a PTHrP-secreting pancreatic neuroendocrine tumour, with hypercalcaemic crisis, pre-eclampsia, and renal failure
}

\author{
P Abraham, S H Ralston, M Hewison, W D Fraser, J S Bevan
}

Postgrad Med J 2002;78:752-754

Severe hypercalcaemia during pregnancy is rare and most cases are secondary to hyperparathyroidism. This is the first report of a parathyroid hormone related protein (PTHrP) secreting neuroendocrine tumour of the pancreas manifesting with severe hypercalcaemia during pregnancy. Measurement of PTHrP was useful in both the diagnosis and follow up of our patient and should be considered in the diagnostic workup of patients with unexplained hypercalcaemia. A raised PTHrP concentration is a strong indicator of malignancy.

S evere hypercalcaemia is rare during pregnancy. Most cases are due to hyperparathyroidism but there are fewer than 150 patients reported in world literature. ${ }^{1}$ There have been two reports of the milk alkali syndrome ${ }^{2}$ and four reported cases of parathyroid carcinoma during pregnancy. Other cases of malignancy related hypercalcaemia in pregnancy are very rare.

Parathyroid hormone related protein (PTHrP) was first isolated in 1987 from cancer cell lines and a tumour associated with hypercalcaemia, and is now considered to be the main mediator of humoral hypercalcaemia of malignancy. ${ }^{45}$ The placenta (during pregnancy) and mammary glands (postpartum) are important physiological sources of PTHrP. ${ }^{6}$

We report a case of extreme hypercalcaemia manifesting during pregnancy. The hypercalcaemia was associated with raised levels of 1,25-dihydroxyvitamin $\mathrm{D}_{3}\left(\mathrm{l}, 25(\mathrm{OH})_{2} \mathrm{D}_{3}\right)$ and was eventually found to be due to a PTHrP secreting pancreatic neuroendocrine tumour.

\section{CASE REPORT}

A 25 year old woman presented at 29 weeks' gestation with altered consciousness, headache, hypertension and proteinuria, and was initially thought to have pre-eclampsia. She was noted to have taken $1 \mathrm{~g}$ of mefenamic acid in divided doses during the two days before presentation.

Her initial investigations showed a serum calcium adjusted for albumin of $5.9 \mathrm{mmol} / \mathrm{l}$ (reference range 2.2-2.6). A retrospective measurement of calcium at 19 weeks' gestation was obtained at $2.33 \mathrm{mmol} / \mathrm{l}$. Her serum phosphate was raised at $2.07 \mathrm{mmol} / \mathrm{l}$ (reference range $0.7-1.2$ ), probably as a result of her renal impairment. She had renal failure with a serum creatinine of $328 \mu \mathrm{mol} / \mathrm{l}$ (reference range 60-110) and her 24 hour urinary protein was $9.09 \mathrm{~g}$. Parathyroid hormone was undetectable using a two site immunoradiometric assay (Diagnostic Product Corporation Immulite, Los Angeles USA).

Abbreviations: $1,25(\mathrm{OH})_{2} \mathrm{D}_{3}, 1,25$-dihydroxyvitamin $\mathrm{D}_{3} ; 25(\mathrm{OH}) \mathrm{D}_{3}$ 25 -hydroxyvitamin $\mathrm{D}_{3} ;$ PTHrP, parathyroid hormone related protein
Her early management consisted of an emergency caesarean section followed by transfer to the intensive therapy unit. She was given five intravenous doses of pamidronate $15 \mathrm{mg}$ twice daily. In the postpartum period calcium decreased rapidly after pamidronate and she required calcium supplements for one month. The calcium decreased to a nadir of $1.9 \mathrm{mmol} / \mathrm{l}$ then subsequently steadily increased to $2.68 \mathrm{mmol} / \mathrm{l}$ at 12 months and $2.76 \mathrm{mmol} / \mathrm{l}$ at 15 months. Her renal function improved rapidly with serum creatinine decreasing to $99 \mu \mathrm{mol} / \mathrm{l}$ at 10 days but the proteinuria took six months to normalise.

Serum parathyroid hormone concentrations were undetectable on three occasions between three and 12 months postpartum while the patient remained significantly hypercalcaemic at the time (fig 1). Measurement of serum vitamin D metabolites showed a normal 25-hydroxyvitamin $\mathrm{D}_{3}$ $\left(25(\mathrm{OH}) \mathrm{D}_{3}\right)$ at $19 \mathrm{nmol} / \mathrm{l}$ (reference range $15-100$ ) with a $1,25(\mathrm{OH})_{2} \mathrm{D}_{3}$ level in the upper end of the normal range at 97 $\mathrm{nmol} / \mathrm{l}$ (reference range 20-120). Because of these results, extrarenal vitamin $\mathrm{D}_{3}$ production secondary to granulomatous disease or lymphoma was considered as a possible cause of the hypercalcaemia. Serum angiotensin converting enzyme was normal at $38 \mathrm{U} / \mathrm{l}$ (reference range 8-52U/1) and chest radiography did not suggest sarcoidosis. An ultrasound of her abdomen was normal and isotope bone scans performed at one and eight months postpartum were both normal. A myeloma screen was negative. Transilical bone biopsy showed increased osteoclastic activity but no evidence of lymphoma. A whole body computed tomogram at 14 months postpartum showed a $9 \mathrm{~cm}$ pancreatic mass and an ultrasound guided fine needle aspiration of this mass showed results consistent with a neuroendocrine tumour. An octreoscan showed increased

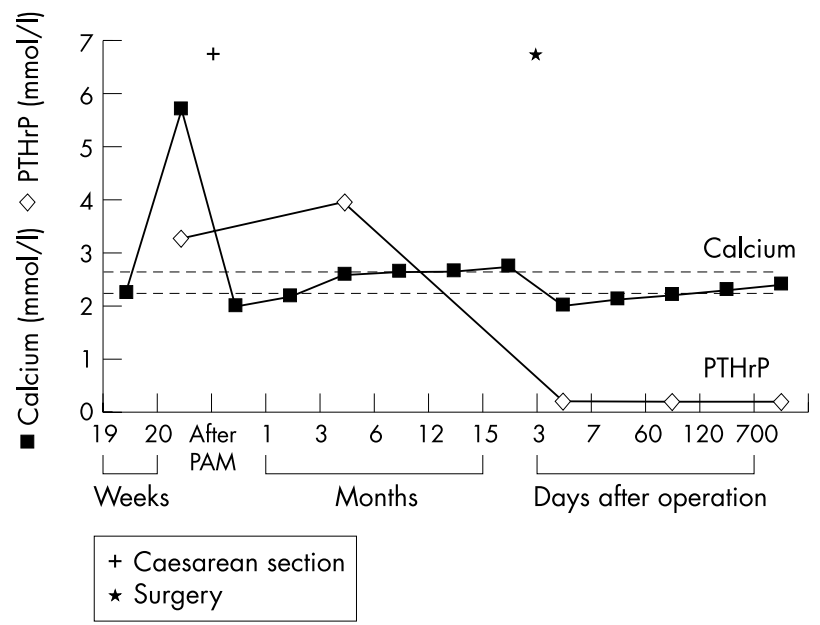

Figure 1 Summary of PTHrP (reference value $<0.5 \mathrm{pmol} / \mathrm{l}$ ) and serum calcium (reference range 2.2-2.6 mmol/l) concentrations over two years (PAM, pamidronate) 
Table 1 Vitamin D challenge test (performed by administering $2000 \mathrm{IU}$ of 25 -hydroxyvitamin $\mathrm{D}_{3}$ $\left(25(\mathrm{OH}) \mathrm{D}_{3}\right)$ for 10 days with alternate day measurement of calcium and vitamin $\mathrm{D}$ metabolites)

\begin{tabular}{llll}
\hline Day & $\begin{array}{l}\text { Calcium } \\
\text { (RR 2.2-2.6 mmol/I) }\end{array}$ & $\begin{array}{l}25(\mathrm{OH}) \mathrm{D}_{3} \\
(\mathrm{RR} 15-100 \mathrm{pmol} / \mathrm{I})\end{array}$ & $\begin{array}{l}1,25(\mathrm{OH})_{2} \mathrm{D}_{3} \\
(\mathrm{RR} 20-120 \mathrm{pmol} / \mathrm{I})\end{array}$ \\
\hline-2 & 2.13 & 62 & 160 \\
0 & 2.66 & 41 & 239 \\
2 & 2.89 & 66 & 208 \\
4 & 2.97 & 80 & 187 \\
6 & 2.68 & 75 & 212 \\
8 & 3.08 & 85 & 205 \\
10 & 3.15 & 97 & 231 \\
\hline
\end{tabular}

$1,25(\mathrm{OH})_{2} \mathrm{D}_{3}, 1,25$-dihydroxyvitamin $\mathrm{D}_{3} ; R R$, reference range.

uptake in the region of the distal pancreas with no evidence of metastases.

A vitamin D challenge test was performed by administering $2000 \mathrm{IU}$ of $25(\mathrm{OH}) \mathrm{D}_{3}$ for 10 days with alternate day measurement of calcium and vitamin D metabolites (see table 1). This suggested inappropriate activation of vitamin $\mathrm{D}$ since the levels of $1,25(\mathrm{OH})_{2} \mathrm{D}_{3}$ remained raised despite the hypercalcaemia. PTHrP (Diasorin Stillwater, USA) measured immediately and two months postpartum was $3.3 \mathrm{pmol} / \mathrm{l}$ and $3.9 \mathrm{pmol} / \mathrm{l}$ (reference value $<0.5 \mathrm{pmol} / \mathrm{l}$ ). A somatostatin challenge test was performed using octreotide $100 \mu \mathrm{g}$ subcutaneously and the PTHrP decreased from 3.3 to $2.1 \mathrm{pmol} / \mathrm{l}$ in one hour followed by normalisation of the serum calcium.

The patient underwent laparotomy and removal of the pancreatic mass in November 1998. For effective tumour removal a splenectomy was also required. Histology and PTHrP immunostaining showed a neuroendocrine tumour with positive immunocytochemical staining using a PTHrP antibody. Staining for the $1 \alpha$-hydroxylase enzyme was negative.

Postoperatively serum calcium (fig 1) and PTHrP levels normalised and remained normal after two years of follow up. Gut hormones were normal and vitamin D metabolites returned to reference values.

The baby was also noted to have hypercalcaemia immediately after birth (calcium $3.03 \mathrm{mmol} / \mathrm{l}$ ) but subsequently became hypocalcaemic over the next two days (calcium 1.59 $\mathrm{mmol} / \mathrm{l}$ ) and required calcium supplementation for about a month. The baby had other problems related to prematurity and required mechanical ventilation for four days along with surfactant. On discharge from the neonatal unit two months after the delivery all metabolic problems had settled, and on subsequent follow up a diagnosis of mild asymmetric cerebral palsy was made which was felt to be mainly due to prematurity.

\section{DISCUSSION}

This is the first reported case of a PTHrP secreting pancreatic neuroendocrine tumour manifesting with a hypercalcaemic crisis during pregnancy. The combination of non-steroidal anti-inflammatory drugs with hypercalcaemia combined to produce a severe acute renal failure and acute deterioration leading to her presentation during pregnancy.

The role of vitamin D metabolites in the pathogenesis of humoral hypercalcaemia of malignancy is a controversial area. While PTHrP binds to the parathyroid hormone type I receptor and mimics virtually all the biological actions of parathyroid hormone, ${ }^{7}$ serum levels of $1,25(\mathrm{OH})_{2} \mathrm{D}_{3}$ in humoral hypercalcaemia of malignancy are frequently suppressed and much lower than in primary hyperparathyroidism. ${ }^{8-10}$ This has led many workers to suggest that PTHrP does not stimulate renal $1 \alpha$-hydroxylase activity in patients with humoral hypercalcaemia of malignancy. ${ }^{11}{ }^{12}$ However Schweitzer et al, ${ }^{12}$ Sato and Takahashi, ${ }^{13}$ and Ralston $e t a l^{8}$ have commented on the fact that $1,25(\mathrm{OH})_{2} \mathrm{D}_{3}$ levels are frequently not suppressed in humoral hypercalcaemia of malignancy, consistent with a stimulatory effect of PTHrP on $1 \alpha$-hydroxylase activity. In keeping with this hypothesis, serum $1,25(\mathrm{OH})_{2} \mathrm{D}_{3}$ levels are increased in various animal models of PTHrP mediated humoral hypercalcaemia of malignancy. ${ }^{14}$ Reasons that have been put forward to explain the lower levels of $1,25(\mathrm{OH})_{2} \mathrm{D}_{3}$ in humoral hypercalcaemia of malignancy compared with primary hyperparathyroidism include the fact that humoral hypercalcaemia of malignancy is often associated with very severe hypercalcaemia and renal failure which can suppress $1 \alpha$-hydroxylase activity ${ }^{16}$ and that many patients with humoral hypercalcaemia of malignancy have low levels of the precursor $25(\mathrm{OH}) \mathrm{D}_{3} .{ }^{8}$

Inappropriate activation of $1,25(\mathrm{OH})_{2} \mathrm{D}_{3}$ production was found in our patient, which almost certainly represented a stimulatory effect of PTHrP on renal $1 \alpha$-hydroxylase activity. Increased production of $1,25(\mathrm{OH})_{2} \mathrm{D}_{3}$ by the tumour itself was excluded by the fact that we found no evidence of $l \alpha$-hydroxylase activity within the tumour.

The reduction in PTHrP and calcium after administration of the somatostatin analogue octreotide is interesting and has been documented previously in other neuroendocrine tumours. ${ }^{17} 18$ This may have therapeutic potential if surgical clearance is not possible. PTHrP measurements were useful in this case in clarifying the diagnosis of the hypercalcaemia and also in follow up as the PTHrP remained reassuringly normal over two years of follow up. PTHrP measurement should be considered in the diagnostic workup of hypercalcaemia of obscure aetiology. A raised PTHrP concentration is strong evidence for the presence of malignancy.

\section{ACKNOWLEDGEMENT}

The PTHrP was measured at the Department of Clinical Chemistry, Royal Liverpool Hospital.

\section{Authors' affiliations}

P Abraham, S H Ralston, J S Bevan, Departments of Endocrinology, Aberdeen Royal Infirmary, Foresterhill, Aberdeen M Hewison, Department of Medicine, University of Birmingham, Queen Elizabeth Hospital, Birmingham

W D Fraser, Department of Clinical Chemistry, Royal Liverpool University Hospital, Liverpool

Correspondence to: Dr P Abraham, Ward 27/28, Aberdeen Royal Infirmary, Foresterhill, Aberdeen AB25 2ZN, UK:

p.abraham@arh.grampian.scot.nhs.uk

Submitted 31 August 2002

Accepted 30 September 2002

\section{REFERENCES}

1 Kelly TR. Primary hyperparathyroidism during pregnancy. Surgery $1991 ; 110: 1028-33$.

2 Kleinman GE, Rodriquez H, Good MC, et al. Hypercalcemic crisis in pregnancy associated with excessive ingestion of calcium carbonate antacid (milk-alkali syndrome): successful treatment with hemodialysis. Obstet Gynecol 1991;78(3 pt 2):496-9.

3 Montoro MN, Paler RJ, Goodwin TM, et al. Parathyroid carcinoma during pregnancy. Obstet Gynecol 2000;96(5 pt 2):841.

4 Suva LJ, Winslow GA, Wettenhall RE, et al. A parathyroid hormone-related protein implicated in malignant hypercalcemia: cloning and expression. Science 1987:237:893-6.

5 Ralston SH, Boyce BF, Cowan RA, et al. Contrasting mechanisms of hypercalcemia in patients with early and advanced humoral hypercalcemia of malignancy. J Bone Miner Res 1989;4:103-11.

6 Ardawi MS, Nasrat HA, BA'Aqueel HS. Calcium-regulating hormones and parathyroid hormone-related peptide in normal human pregnancy and postpartum: a longitudinal study. Eur J Endocrinol 1997:137:402-9.

7 Martin TJ, Suva LJ. Parathyroid hormone-related protein in

Martin TJ, Suva LJ. Parathyroid hormone-related protein in
hypercalcaemia of malignancy. Clin Endocrinol (Oxf) 1989;31:631-47. 8 Ralston SH, Cowan RA, Robertson AG, et al. Circulating vitamin D metabolites and hypercalcaemia of malignancy. Acta Endocrinol (Copenh) 1984;106:556-63.

9 Schilling T, Pecherstorfer M, Blind E, et al. Parathyroid hormone-related protein (PTHrP) does not regulate 1,25-dihydroxyvitamin D serum levels in hypercalcemia of malignancy. J Clin Endocrinol Metab 1993;76:801-3. 
10 Stewart AF, Horst R, Deftos $L$, et al. Biochemical evaluation of patients with cancer-associated hypercalcemia: evidence for humoral and nonhumoral groups. N Engl J Med 1980;303:1377-83.

11 Broadus AE, Mangin M, Ikeda K, et al. Humoral hypercalcemia of cancer. Identification of a novel parathyroid hormone-like peptide. $N$ Engl J Med 1988;319:556-63.

12 Schweitzer DH, Hamdy NA, Frolich M, et al. Malignancy-associated hypercalcaemia: resolution of controversies over vitamin D metabolism by a pathophysiological approach to the syndrome. Clin Endocrinol (Oxf) 1994:41:251-6.

13 Sato H, Takahashi M. Non-Hodgkin's malignant lymphoma of the bone with intracavitary cardiac involvement. Intern Med 1993;32:502-7.

14 Gkonos PJ, Hayes T, Burtis W, et al. Squamous carcinoma model of humoral hypercalcemia of malignancy. Endocrinology 1984;115:2384-90.
15 Insogna KL, Stewart AF, Vignery AM, et al. Biochemical and histomorphometric characterization of a rat model for humoral hypercalcemia of malignancy. Endocrinology 1984;114:888-96.

16 Shaker JL, Krawczyk KW, Findling JW. Primary hyperparathyroidism and severe hypercalcemia with low circulating 1,25-dihydroxyvitamin D. I Clin Endocrinol Metab 1990:71:1305-9.

17 Barhoum M, Hutchins L, Fonseca VA. Intractable hypercalcemia due to a metastatic carcinoid secreting parathyroid hormone-related peptide and interleukin-6: response to octreotide. Am J Med Sci 1999:318:203-5

18 Mantzoros CS, Suva LJ, Moses AC, et al. Intractable hypercalcaemia due to parathyroid hormone-related peptide secretion by a carcinoid tumour. Clin Endocrinol (Oxf) 1997;46:373-5.

\section{BENCH $>$ PRESS}

\section{New PMJ online submission and review system}

am pleased to inform authors and reviewers of Postgraduate Medical Journal's new online submission and review system. Bench $>$ Press is a fully integrated electronic system which uses the internet to allow rapid and efficient submission of manuscripts, and the entire peer review process to be conducted online. Authors can submit their manuscript in any standard word processing software. Graphic formats acceptable are: .jpeg, .tiff, .gif, and .eps. Text and graphic files are automatically converted to PDF for ease of distribution and reviewing purposes. Authors are asked to approve their submission before it formally enters the reviewing process.

To access the system click on "SUBMITTING YOUR MANUSCRIPT" on the PMJ homepage: http://www.postgradmedj.com/ or you can access Bench>Press directly at http://submitpmj.bmjjournals.com/.

We are very excited with this new development and we would encourage authors and reviewers to use the online system where possible. It really is simple to use and should be a big improvement on the current peer review process. Full instructions can be found on Bench>Press and PMJ online. Please contact Natalie Davies, Project Manager, ndavies@bmjgroup.com for further information.

\section{Pre-register with the system}

We would be grateful if all $P M J$ authors and reviewers pre-registered with the system. This will give you the opportunity to update your contact and expertise data, allowing us to provide you with a more efficient service.

\section{Instructions for registering}

1. Enter http://submit-pmj.bmjjournals.com.

2. Click on "Create a new account" in the upper left hand side of the Bench >Press

homepage.

3. Enter your email address in the space provided.

4. Choose a password for yourself and enter it in the spaces provided.

5. Complete the question of your choice to be used in the event you cannot remember

your password at a later time (this will be needed if you forget your password).

6. Click on the "Complete step l" button at the bottom of the screen.

7. Check the email account you registered under. An email will be sent to you with a verification number and URL.

8. Once you receive the email, copy the verification number and click on the URL hyperlink. Enter the verification number in the relevant field. Click on "Verify

me". This is for security reasons and to check that your account is not being used fraudulently.

9 . Enter/amend your contact information, and update your expertise data. 